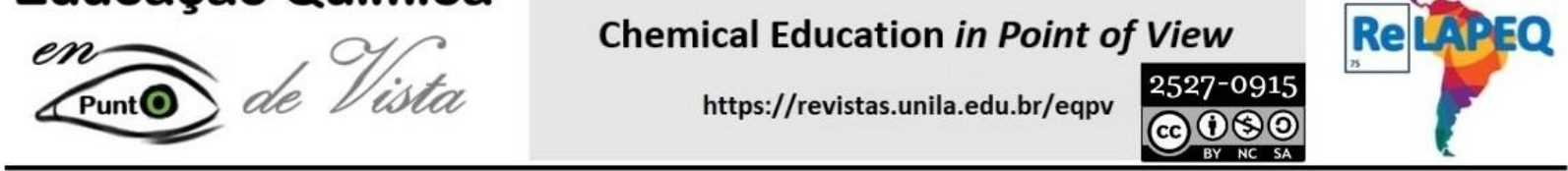

\title{
Prancha temática como ferramenta de inclusão: ensinando a tabela periódica à alunos com deficiência intelectual
}

\section{Cecília Elisa de Sousa Muniz ${ }^{1}$, Antonio Luiz da Silva², Diana Sampaio Bragada ${ }^{3}$, Gilberlândio Nunes da Silva ${ }^{4}$

\footnotetext{
${ }^{1}$ Mestra em Engenharia Química pela Universidade Federal de Campina Grande (UFCG/Brasil). Brasil.

${ }^{3}$ Doutora em Psicologia pela Universidade Federal da Paraíba Professora da Universidade Estadual da Paraíba (UEPB/Brasil).

${ }^{4}$ Mestre em Química pela Universidade Federal do Rio Grande do Norte (UFRN/Brasil)
} \\ ${ }^{2}$ FUNAD - Fundação Centro Integrado de Apoio à Pessoa com Deficiência, João Pessoa, Paraíba,}

\section{Thematic plank as na inclusion tool: teaching the periodic table to students with}

\author{
intellectual disabilities
}

Informações do Artigo

Recebido: 01/09/2020

Aceito: $19 / 12 / 2020$

Palavras-chave:

Ensino de Química; Deficiência Intelectual; Prancha temática.

Key words:

Teaching of the Chemistry; Intellectual Disability; Thematic board.

E-mail: ceciliamuniz.qi@gmail.com

\begin{abstract}
A B S T R A C T
Understanding the scientific concepts of chemistry are a challenge for high school students, especially for students with intellectual disabilities. Recognizes itself, therefore, the need to develop new methodologies that are appropriate to the specificities of this group is recognized. This research aimed to develop a thematic board to assist students with intellectual disabilities in teaching / learning the periodic table. For this, the picto4me software was used in the choice and arrangement of the figures on the thematic board. The content of the periodic table has been worked by observing the chronological sequence of the textbooks. After being built, the thematic board was used by a student with intellectual disabilities and his level of learning was checked through the increased of the number of the correct answers to the questions provided in a specific exercise. The results obtained evidence the validity of the thematic board, because in addition to assisting in learning, it generated new questions for the student, a way to evoke more elaborate thoughts.
\end{abstract}

INTRODUÇÃO 


\section{Educação Química}
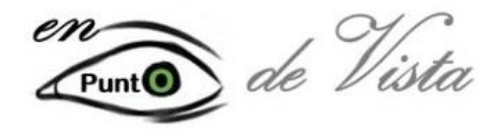

\section{A inclusão como meta e obrigação ético-escolar}

O conceito de educação inclusiva surgiu a partir de 1994, com a Declaração de Salamanca, cujo principal objetivo é proporcionar oportunidades iguais de ensinoaprendizagem aos alunos com necessidades educacionais especiais (NEE) dentro do ensino regular (MENDONÇA, 2015).

Com a Constituição Federal de 1988 e com a Política Nacional de Inclusão instituída em 2007 as pessoas com necessidades educativas especiais passaram a ter seus direitos educacionais reconhecidos e assegurados por lei, o que implica na possibilidade de alunos com deficiência estarem inseridos nas escolas de ensino regular, com acesso ao atendimento educacional especializado (AEE), ofertado pela mediação de profissionais capacitados teórica e metodologicamente para a educação inclusiva (SAMPAIO, 2017).

Porém, lidar com as especificidades desses alunos permanece um desafio para os professores e para a escola do ensino regular. Uma das maiores dificuldades está relacionada às crianças e adolescentes que apresentam impedimentos na comunicação, que podem ser causados por questões de ordem sensorial, física ou cognitiva. Nesses casos, os principais desafios são: garantir a comunicação e a relação interpessoal dos alunos com NEE e os demais estudantes, desenvolver metodologias adequadas as diferentes necessidades desse grupo de alunos de modo que eles compreendam o máximo possível do conteúdo didático trabalhado em sala de aula (SILVA, 2013).

\section{PARA PENSAR A INCLUSÃO DE ALUNOS COM DEFICIÊNCIA INTELECTUAL}

Dentre os alunos com deficiências inseridos no ensino regular, aqueles que apresentam deficiência intelectual representam a maioria nas estatísticas nacionais, conforme demonstram Meletti e Bueno (2013). Mas, o que caracteriza a deficiência intelectual? De acordo com a American Psychiatric Association (2014) a deficiência intelectual é caracterizada por prejuízo em habilidades intelectuais, tais como: pensamento abstrato, resolução de problemas, aprendizagem acadêmica e raciocínio. É comum ocorrerem déficits no funcionamento adaptativo, o que pode dificultar o desenvolvimento da autonomia e limitações no ajuste do comportamento às diversas situações sociais. Como reza a literatura nacional e internacional (HONORA; FRIZANCO, 2008), a pessoa com deficiência intelectual apresenta desajustes em pelo menos duas áreas de habilidades cotidianas, a saber: comunicação, autocuidado, vida no lar, adaptação social, saúde e segurança, uso de recursos 

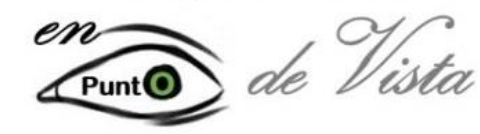

da comunidade, funções acadêmicas, lazer e trabalho. Além disso, esta sintomatologia deve se manifestar ao longo do período de desenvolvimento, não ultrapassando a idade de 18 anos.

Para se chegar a um entendimento de que um determinado ser humano é pessoa com deficiência intelectual um caminho longo de investigação precisa ser observado. Além dos critérios clínicos e das habilidades adaptativas acima apresentadas, o funcionamento intelectual também é avaliado por meio de testes padronizados, a partir dos quais se aufere o Quociente de Inteligência (QI). Segundo o manual da AAIDD (2010), os resultados dos testes de QI e da avaliação global, devem levar em consideração que as especificidades apresentadas pelo indivíduo, no que diz respeito às suas habilidades intelectuais e aos indicadores de adaptação, devem ser comparadas a seus pares etários, oriundos do mesmo contexto comunitário e com acesso semelhante às oportunidades acadêmicas e de desenvolvimento social.

É evidente que uma avaliação apropriada deve considerar a variedade cultural, a variação linguística, as modalidades de comunicação, as condições sensoriais, motoras e comportamentais presentes em cada indivíduo. A importância da avaliação está, sobretudo, na possibilidade de se identificar as limitações e habilidades de cada indivíduo no conjunto de sua existência. A avaliação servirá como empreendimento auxiliar no desenvolvimento de um perfil de apoio personalizado necessário a cada pessoa por um determinado período de tempo. Nesse sentido, pode-se enfatizar que a avaliação contribuirá para que a vida da pessoa com deficiência intelectual melhore (AAIDD, 2010).

Entre as dificuldades vivenciadas pelos alunos com deficiência intelectual destaca-se a escolarização. Muitos não conseguem aprender a ler e a escrever na idade esperada. Alguns não conseguem se apropriar de conteúdos acadêmicos mais complexos. Além das limitações de aprendizagem existem também aquelas que são da estrutura do ensino/aprendizagem. Muito frequentemente os alunos com deficiência intelectual não têm acesso mínimo, no ambiente escolar, aos recursos necessários, tais como: tecnologias assistivas, currículos flexíveis, adaptados ou diferenciados, metodologias e recursos didáticos que se adaptem às suas necessidades específicas de ensino-aprendizagem (ANACHE; RESENDE, 2016). Assim, apesar das políticas educacionais em vigor assegurarem a inclusão social de todas as pessoas com necessidades educacionais especiais, aquelas com deficiência intelectual ainda permanecem sendo excluídas por serem consideradas pessoas incapazes de aprender.

Lembra-se, contudo, que aqui não se estar a fazer acusações levianas contra a escola ou mesmo contra o professorado. Sabe-se bem das condições materiais das escolas, tanto no que tange às necessidades regulares quanto no que se refere às carências especiais. Entendese que as dificuldades não se resumem ao ensinar e ao aprender. Aliás, Araújo e Almeida (2014) destacam os problemas enfrentados pelos professores para ensinar os conteúdos escolares convencionais e avaliar a aprendizagem dos alunos com deficiência intelectual, 

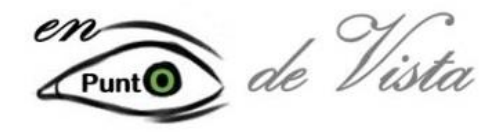

sobretudo quando eles já estão em ciclos de estudos mais avançados e não possuem os requisitos necessários para estarem nesse nível de ensino. O que fazer com alunos que chegam ao sétimo ano e não sabem ler?

Salienta-se, então, que o processo educativo deve configurar-se de modo dinâmico e motivador, colocando o aluno como sujeito do processo. Faz-se necessário propiciar todas as condições para que o aluno com deficiência intelectual adquira e desenvolva habilidades que possibilitem sua melhor inclusão social, fazendo, portanto, com que ele exerça o papel de cidadão na sociedade (MIRANDA; PINHEIRO, 2016; GLAT; FERNANDES, 2005).

Destaca-se que, na Educação Inclusiva, talvez mais do que em outras modalidades educativas, o professor é um dos agentes mais importantes, pois, sem ele(a), as metodologias, estratégias e recursos didáticos não serão suficientes para um bom processo de ensinoaprendizagem (SAMPAIO, 2017).

\section{A PRANCHA TEMÁtICA DE COMUNICAÇÃO COMO INSTRUMENTO DE ENSINO/APRENDIZAGEM}

Nesse contexto, os sistemas alternativos de comunicação parecem ser uma opção eficaz para auxiliar no ensino-aprendizagem dos alunos com deficiência intelectual. Dentre esses recursos, a prancha temática de comunicação destaca-se como uma excelente ferramenta para auxiliar o professor, de qualquer nível escolar, no ensino dos conteúdos escolares convencionais, já que pode ser personalizada de acordo com as condições motoras de cada aluno, com os conteúdos e com as temáticas a serem trabalhados (ALENCAR; ZAPOROSZENKO, 2008; CROCETTI; NASCIMENTO, 2014).

As pranchas temáticas de comunicação são recursos pedagógicos de uso disseminado entre os profissionais da educação que trabalham com crianças com necessidades educacionais especiais, principalmente aquelas que apresentam dificuldade para se comunicar. Essa ferramenta é muito utilizada para que a criança por meio das figuras consiga expressar seus sentimentos e necessidades mais comuns do dia-a-dia, como: estar com fome ou com vontade de ir ao banheiro.

Outra qualidade da prancha é o seu baixíssimo custo, visto que sua construção requer materiais simples, tais como: cadernos, álbuns, fichários, pastas, cartões e o uso de figuras, que podem ser retiradas da internet, livros ou revistas (JOHNSON, 1998). As imagens devem ser organizadas de maneira sequencial e lógica para auxiliar o aluno a compreender melhor o conteúdo que o professor irá trabalhar em sala de aula com os demais alunos que não tem nenhuma necessidade educacional especial. 


\section{Educação Química}
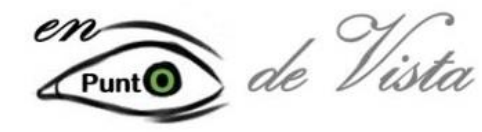

Enquanto recurso metodológico, a prancha temática pode ser construída em conjunto com o aluno, inclusive o professor da sala de atendimento educacional especializado (AEE) pode auxiliar o docente do ensino regular na confecção deste recurso, tornando o ensino integrado entre sala de aula regular e o AEE.

Constituída por uma sequência de figuras comuns do dia-a-dia do aluno, a prancha temática de comunicação, caracteriza-se como um conjunto de pistas mentais que auxiliam o aluno com deficiência intelectual a compreender melhor os conceitos teóricos dos conteúdos escolares trabalhados, uma vez que esse grupo de alunos pode apresentar dificuldades de fala, leitura, compreensão e de interpretação, principalmente quando estes conteúdos são inerentes às áreas das ciências da natureza e suas tecnologias.

Entretanto, a adoção da prancha temática como ferramenta útil para auxiliar tanto o professor quanto os alunos com algum tipo de necessidade educacional especializado, inseridos no ensino fundamental e médio, no processo de ensino-aprendizagem ainda não foi suficientemente difundida.

\section{A PRANCHA teMÁtICA PARA O ENSINO de QUímiCA A ALUNOS COM DEFICIÊNCIA INTELECTUAL}

Dentre os conteúdos das ciências da natureza e suas tecnologias, abordados tanto no ensino fundamental quanto no ensino médio, os de química costumam ser considerados de difícil compreensão para muitos alunos, inclusive por aqueles que não possuem nenhuma necessidade educacional especial.

Em se tratando especificamente de alunos com deficiência intelectual a dificuldade de compreensão torna-se ainda maior, requerendo do professor o uso de metodologias e recursos didáticos que facilitem o processo de ensino-aprendizagem desses conteúdos que envolvem conhecimentos científicos complexos, desmistificando e aproximando ao máximo os conceitos químicos do cotidiano do aluno.

Dentre os conteúdos de química trabalhados na educação básica o de Tabela Periódica, ministrado no $9^{\circ}$ ano do ensino fundamental, pode ser considerado um dos mais importantes, pois trata do estudo dos elementos químicos, base de toda química e pré-requisito para os conteúdos ministrados em todo o ensino médio.

Embora seja considerado um conteúdo básico da química, o processo de ensinoaprendizagem do conteúdo de Tabela Periódica pode ser complexo, principalmente quando o aluno tem dificuldade de escrita, leitura, raciocínio lógico e de compreensão de conceitos distantes de sua realidade ("conceitos abstratos"), como é o caso dos alunos com deficiência intelectual. Este conteúdo compreende o estudo dos elementos químicos, sua organização e classificação periódica, sua distribuição em camadas eletrônicas e em famílias, nomenclaturas, 


\section{Educação Química}
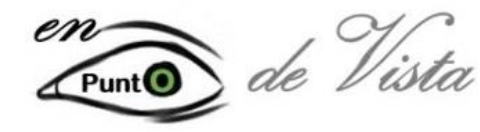

configuração eletrônica, níveis energéticos, orbitais eletrônicos e propriedades periódicas (raio atômico, energia de ionização, afinidade eletrônica), que requerem do aluno um nível de compreensão elevado. Então fica o questionamento, poderia um aluno com deficiência intelectual atingir esse nível de compreensão sem o auxílio de algum recurso metodológico? Provavelmente não.

Para o entendimento da química, uma estratégia pedagógica que muito contribui é a articulação entre teoria e prática. Esta conexão entre o conteúdo acadêmico e elementos pertencentes ao dia-a-dia dos alunos é contemplada na confecção da prancha temática, pois, as imagens selecionadas são partes integrantes da rotina dos estudantes. Assim sendo, a utilização de figuras e símbolos presentes na prancha tem como finalidade facilitar a aprendizagem do conteúdo através da materialização de conceitos abstratos em pistas visuais.

Considerando o que foi exposto, o presente trabalho teve como finalidade elaborar uma prancha temática para auxiliar os professores de química no ensino do conteúdo de tabela periódica e aplicá-la a um aluno com deficiência intelectual para verificar se o uso deste recurso corroborou para a sua aprendizagem.

\section{MATERIAIS E MÉTODOS}

\section{Escolha do conteúdo de química}

Optou-se por trabalhar com o conteúdo de Tabela Periódica, base da química e prérequisito para todos os conteúdos subsequentes lecionados no ensino médio, sendo geralmente ministrado aos alunos do $9^{\circ}$ ano do ensino fundamental, onde a presença de alunos com deficiência intelectual ainda é mais numerosa que no nível médio.

É importante salientar que a construção da prancha temática só foi iniciada após contato com uma professora da sala de atendimento eeducacional especializado de uma Escola da Rede Estadual da cidade de Campina Grande-PB, que informou acerca do histórico do processo de aprendizagem, das habilidades e características do aluno selecionado para participar da atividade aqui descrita.

\section{Confecção do recurso de comunicação alternativa (prancha temática)}

Para a confecção do recurso de comunicação alternativa (prancha temática), recorreuse ao software Picto4me aplicativo on-line do Google, o qual é utilizado para construção e edição de pranchas de comunicação alternativa. A prancha temática é um recurso alternativo 

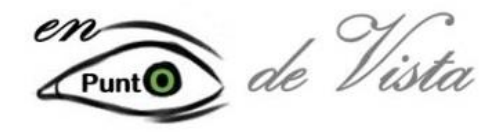

de comunicação constituído por uma sucessão de figuras, dispostas uma após a outra, com a finalidade de expressar, traduzir e representar visualmente o conceito teórico descrito em cada palavra e subsequentemente em uma frase.

Para a confecção da prancha temática trabalhando o conteúdo de Tabela Periódica seguiu-se a sequência cronológica adotada pelos livros didáticos, com a finalidade de proporcionar ao professor do ensino regular a possibilidade de trabalhar esse conteúdo de modo simultâneo, atendendo o aluno de deficiência intelectual e o resto da turma. A prancha temática atuará como recurso de ensino auxiliando o professor a transmitir o conteúdo de Tabela Periódica de modo mais simplificado para esse aluno especial, como instrumento metodológico ajudando o aluno com deficiência intelectual a desmistificar os conceitos químicos compreendendo-o melhor, e como ferramenta inclusiva ao garantir a esse aluno com necessidades educacionais especiais a mesma possiblidade de aprender o conteúdo de química que os demais estudantes.

Na confecção da prancha temática de comunicação de início foram trazidos exemplos de elementos químicos que podem ser encontrados no cotidiano do aluno. Em seguida foram apresentados os conceitos de número atômico, organização dos elementos químicos na tabela periódica em famílias e períodos, nomenclaturas dessas famílias, as configurações eletrônicas dos elementos químicos, camada de valência, níveis energéticos, orbitais eletrônicos e propriedades periódicas (raio atômico, afinidade eletrônica e energia de ionização).

Nos livros didáticos o conteúdo de Tabela periódica costuma ser divido em tópicos ou seções, pensando nisso, a confecção da prancha temática foi feita em capítulos para auxiliar tanto o professor de química, no momento de ministrar a aula, quanto o aluno com deficiência intelectual, de modo que ele adquira os conceitos químicos gradativamente.

Depois de finalizada a prancha temática de comunicação foi impressa em papel cartão e organizada na forma de um caderno/livro.

\section{Aplicação do recurso de comunicação alternativa (prancha temática) a um aluno com deficiência intelectual}

A prancha temática foi aplicada a um aluno com deficiência intelectual que atualmente cursa $01^{\circ}$ ano do ensino médio em uma Escola da Rede Estadual de Ensino da cidade de Campina Grande - Paraíba, com consentimento prévio do aluno e dos responsáveis pela instituição de ensino.

A aplicação do recurso de comunicação, objeto de estudo nesta pesquisa, foi feita na sala de atendimento educacional especializado na presença da professora responsável pelo mesmo e teve duração de uma hora aproximadamente. Em conjunto com a prancha temática 


\section{Educação Química}
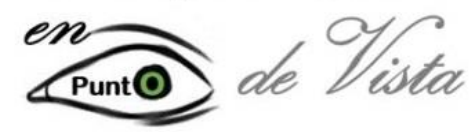

Chemical Education in Point of View

https://revistas.unila.edu.br/eqpv

desenvolvida utilizou-se como recurso didático duas tabelas periódicas, uma convencional e outra chamada tabela periódica do cotidiano, conforme Figuras 1 e 2, respectivamente.

Figura 1: Tabela Periódica convencional

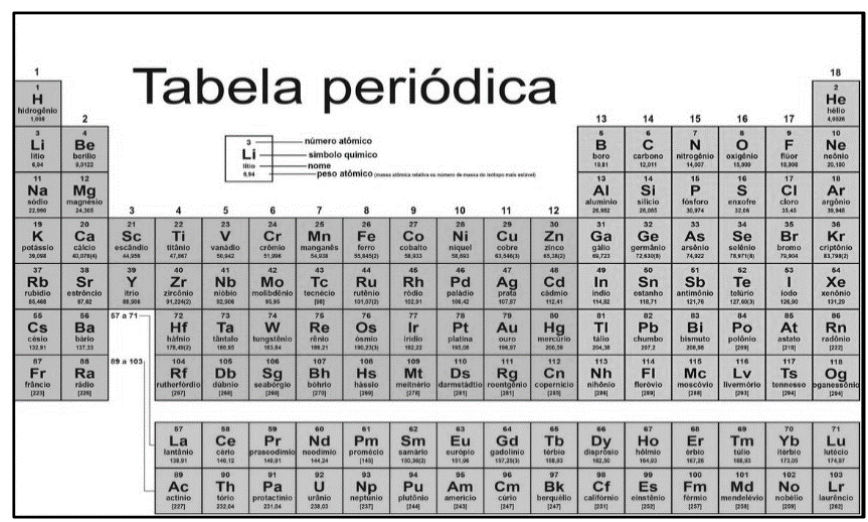

Fonte: (GOOGLE IMAGENS, 2020).

Figura 2: Tabela Periódica do cotidiano

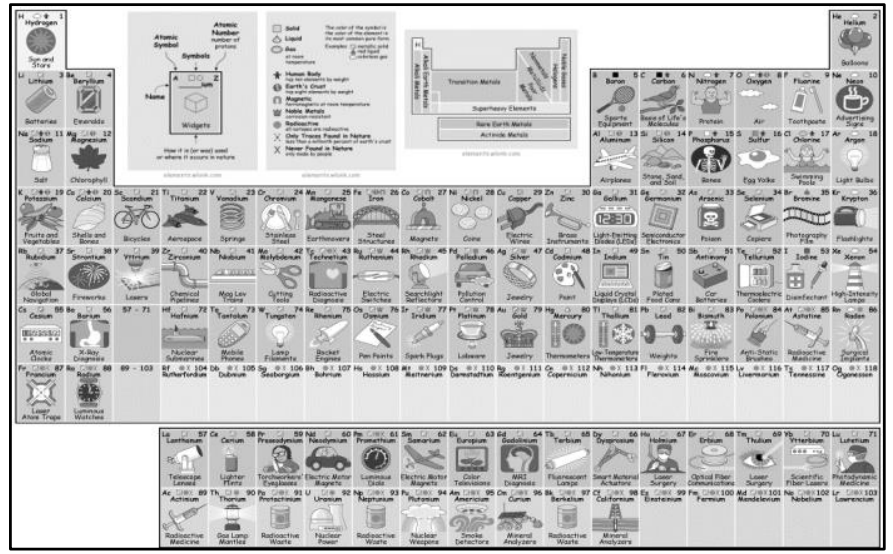

Fonte: (HOLZLE, 2020).

De início foi apresentado a Roberto ${ }^{1}$ as duas tabelas periódicas, falou-se sobre a construção da tabela periódica, o porquê dela ter sido construída, sua finalidade, etc. Fazendo uso da tabela periódica do cotidiano, Figura 2, foram identificados objetos do dia-a-dia do aluno que são constituídos por um ou mais elementos químicos contidos na tabela periódica.

Em seguida somado ao uso das tabelas periódicas apresentou-se a prancha temática e foram trabalhados os tópicos iniciais do conteúdo de tabela periódica (número atômico, organização dos elementos químicos na tabela periódica em famílias e períodos e

\footnotetext{
${ }^{1}$ No decorrer do artigo o participante da pesquisa será referido pelo pseudônimo Roberto como forma de assegurar seu anonimato.
} 


\section{Educação Química}
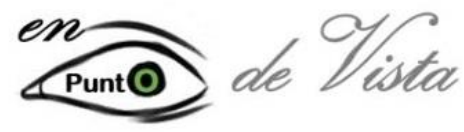

nomenclatura das famílias). A aplicação da mesma foi feita a partir da leitura dos conceitos com a apresentação das figuras ao aluno, permitindo que ele associasse cada termo/palavra a sua respectiva figura, construindo simultâneamente o conhecimento acerca do conteúdo de tabela periódica.

\section{Avaliação da aprendizagem do aluno com deficiência intelectual}

Para que fosse verificado o efeito da utilização do recurso didático, objeto desta atividade, na aprendizagem de Roberto aplicou-se um questionário/exercício de múltipla escolha adequado ao nível de compreensão do aluno, Figura 3, composto de questões com enunciados curtos e objetivos, e respostas na forma de figuras, as quais eram semelhantes às utilizadas na prancha temática, para adaptar-se à dificuldade de escrita do aluno participante. O mesmo questionário foi aplicado antes da utilização da prancha temática como recurso didático, para verificar o conhecimento prévio de Roberto acerca do conteúdo de tabela periódica, e depois para analisar se o uso desta metodologia alternativa trouxe contribuições significativas para sua aprendizagem.

Para avaliar a aprendizagem de Roberto, considerou-se o índice de acertos, antes e após o uso da prancha temática de comunicação.

Figura 3- Questionário aplicado ao aluno com deficiência intelectual

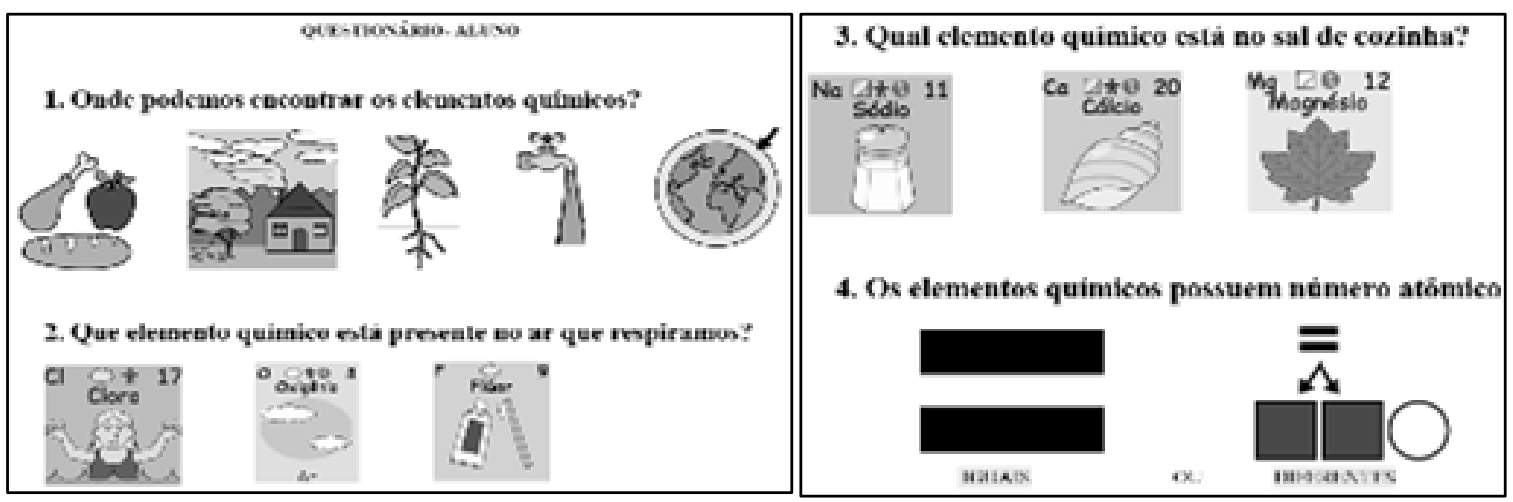

\section{RESULTADOS E DISCUSSÕES}

\section{Elaboração da prancha temática de comunicação}

Percebendo a necessidade de mudanças na prática letiva e buscando formas alternativas que possam tornar o ambiente escolar mais produtivo para professores de química e alunos com necessidades educativas especiais, principalmente aqueles com deficiência intelectual e tornar essa área do conhecimento acessível, elaborou-se uma 


\section{Educação Química}
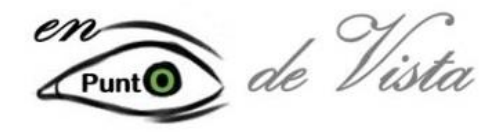

prancha de comunicação para trabalhar o conteúdo de Tabela Periódica, que é o fundamento de toda a química.

A escolha da prancha foi motivada pelos benefícios ocasionados por esse instrumento para a aprendizagem dos estudantes. Conforme diz Dias, Souza e Cruz (2018) a utilização de pranchas temáticas de comunicação no ensino de ciências pode favorecer o desempenho não só de alunos com necessidades educacionais especiais, como é o caso daqueles com deficiência intelectual, mas também dos demais alunos, por se tratar de uma metodologia que alia a visualização de figuras comuns do seu dia-a-dia a organização dos conhecimentos de maneira concreta e gradativa. Os autores acreditam ainda que os alunos serão confrontados positivamente com a forma de apresentação dos conteúdos diferente do usual e que trará possibilidade de uma percepção diferente da aula e também da escola.

A prancha temática foi construída utilizando figuras simples e comuns, que pudessem ser reconhecidas por todos os possíveis alunos que futuramente venham a utilizar este recurso. Cada figura representa uma palavra ou expressão, e a sequência delas forma uma frase. Por seguir em conformidade com a sequência lógica de conhecimento apresentada nos livros didáticos, quando o professor trabalhar esse mesmo conteúdo em sala de aula, o aluno com deficiência intelectual poderá utilizar este recurso didático para acompanhar e compreender melhor através das figuras o conhecimento que está sendo repassado.

A prancha temática proposta está organizada na forma de um caderno ou livro, conforme Figura 4, permitindo que o aluno com deficiência intelectual faça uso do mesmo durante as aulas, e adquira o conhecimento de modo gradativo e sequencial. Alencar e Zaporoszenko (2008) afirmam que a utilização das figuras por meio da prancha temática para o processo de ensino-aprendizagem deve ser feita em etapas, de modo que o conhecimento seja adquirido de maneira gradativa, onde a medida que o aluno se apropria do conceito expresso em uma determinada imagem o professor dispõe de mais imagens que contenham mais informações acerca do conteúdo que está sendo trabalhado. Esse processo de reconhecimento deve ser feito sempre que se introduz uma nova imagem. Sabendo disso, a prancha temática de comunicação desenvolvida na presente pesquisa foi dividida em 11 capítulos para trabalhar gradativamente desde os conceitos iniciais sobre os elementos químicos até as suas respectivas propriedades periódicas. 


\section{Educação Química}

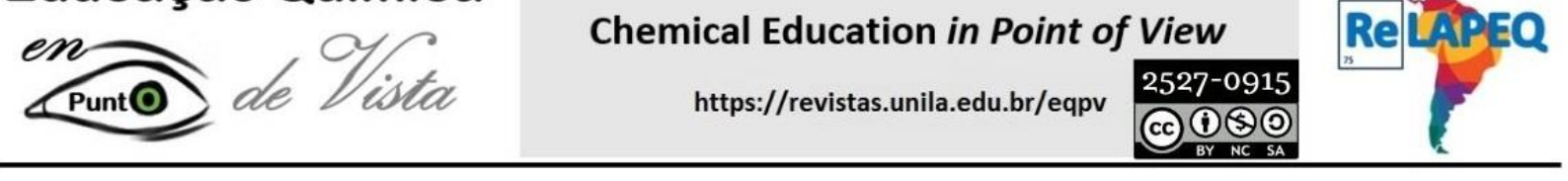

Figura 4- Prancha temática de comunicação desenvolvida.
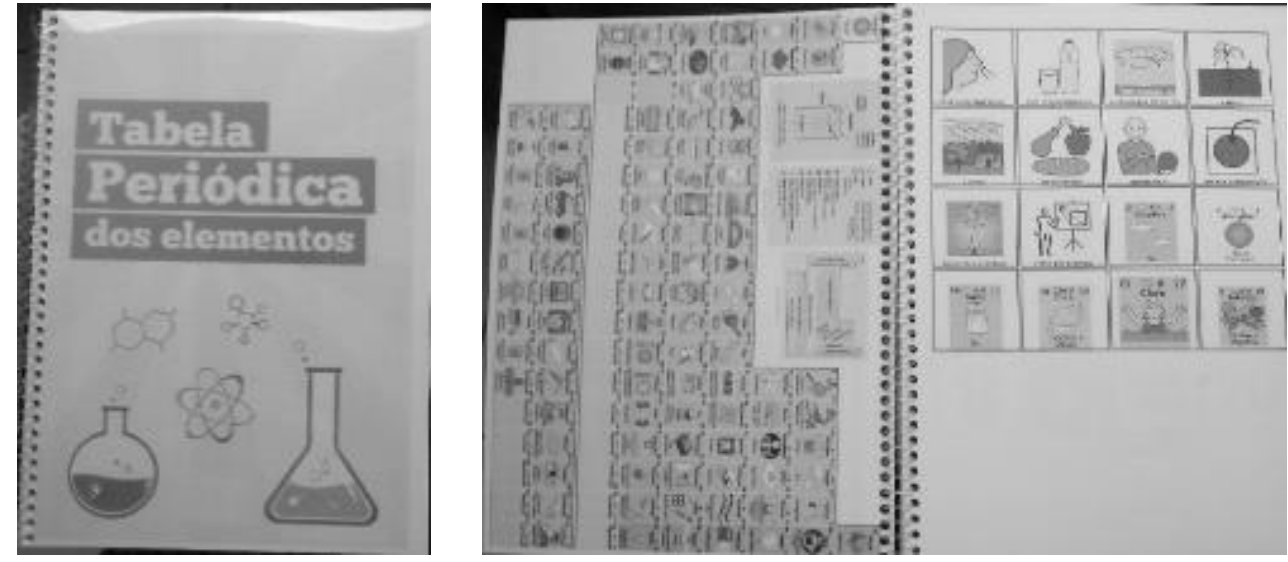

No capítulo I da prancha temática, conforme Figura 5, apresentam-se alguns exemplos de elementos químicos familiares ao aluno com deficiência intelectual.

Figura 5- Elementos químicos no cotidiano do aluno (cap.l)

Os elementos químicos no nosso dia-a-dia

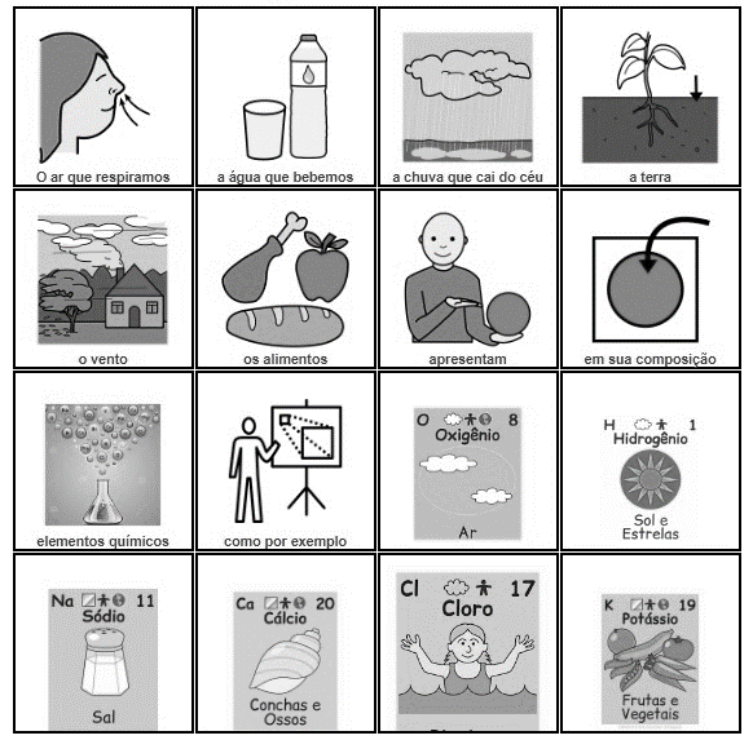

Nos capítulos II e III da prancha temática, conforme Figuras 6 e 7 respectivamente, trabalhou-se os conceitos de número atômico, propriedade intrínseca de cada elemento químico, e a organização dos elementos químicos em períodos e famílias. 


\section{Educação Química}

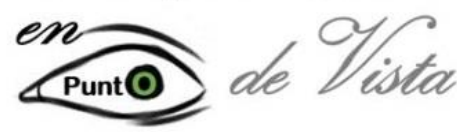

Chemical Education in Point of View

2527-0915

https://revistas.unila.edu.br/eqpv

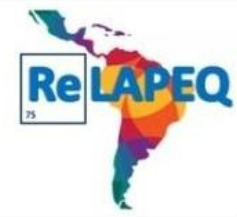

Figura 6 - Número atômico (Cap. II)

Figura 7- Organização periódica dos elementos químicos (Cap. III)
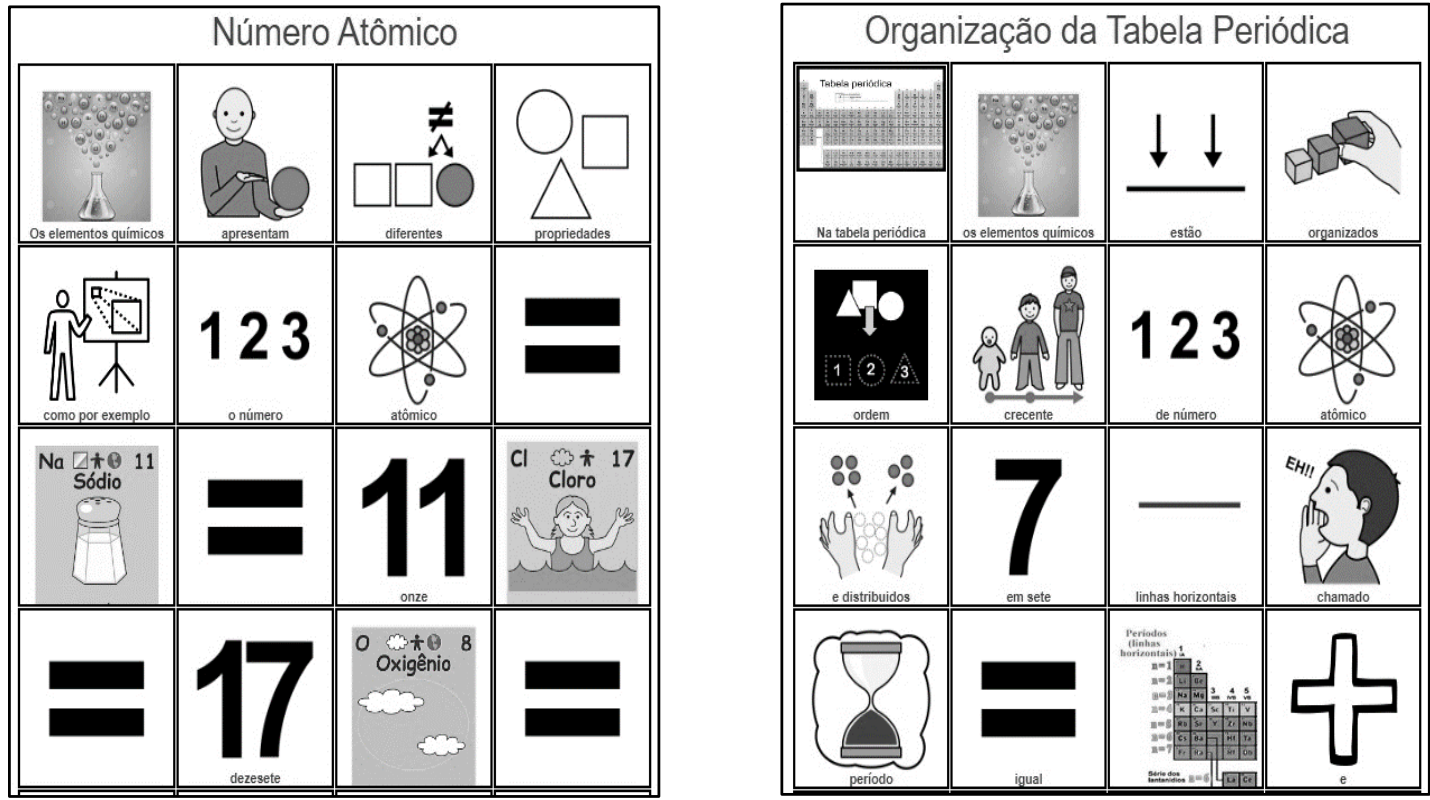

No capítulo IV trabalhou-se a nomenclatura das famílias dos elementos químicos e no $\checkmark$ o conceito de camada eletrônica, conforme Figuras 8 e 9, respectivamente.

Figura 8 - Nomenclaturas das famílias (Cap.

IV)

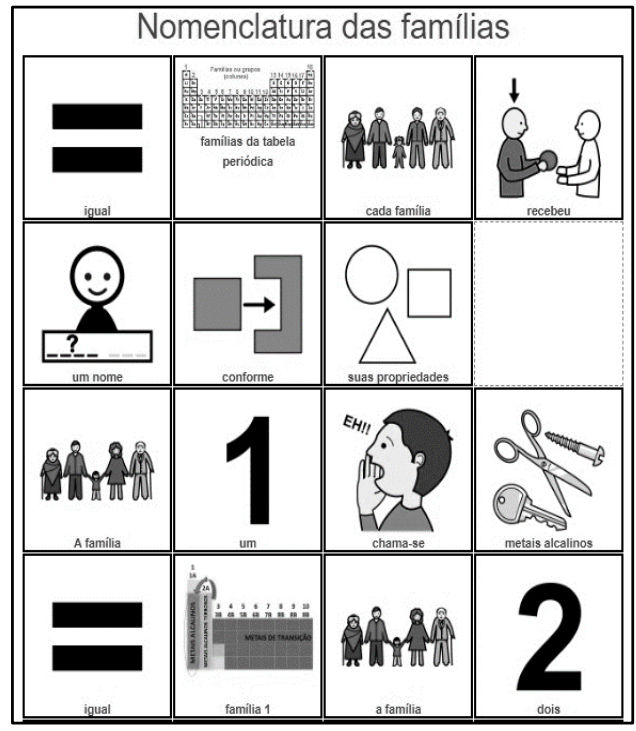

Figura 9 - Camada eletrônica dos elementos

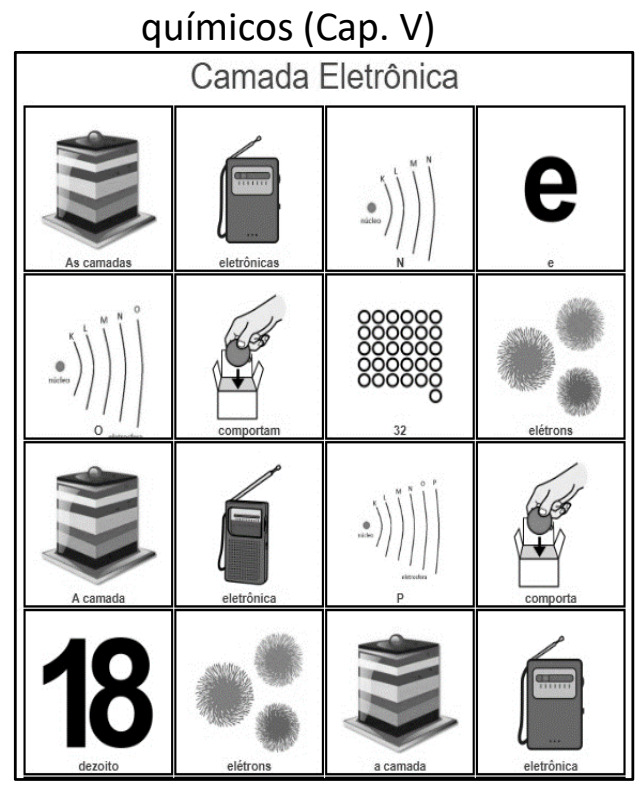

No capítulo VI da prancha temática, Figura 10, trabalhou-se a configuração eletrônica dos elementos químicos, bem como a distribuição dos elétrons em cada uma das camadas 


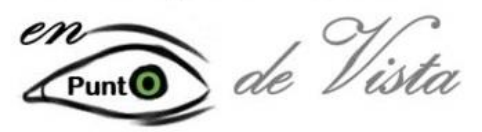

eletrônicas. No capítulo VII, conforme Figura 11, foram apresentados os conceitos de orbitais eletrônicos, níveis energéticos e distribuição dos elétrons nos orbitais s, $p, d$ e f.

No capítulo VIII, conforme Figura 12, trabalhou-se a distribuição eletrônicas dos elementos químicos e o conceito de camada de valência. No capítulo XIX, Figura 13, introduziu-se o conceito da propriedade periódica raio atômico, demonstrando como ele se comporta ao longo da tabela periódica.

Figura 10 - Configuração eletrônica (Cap. VI)

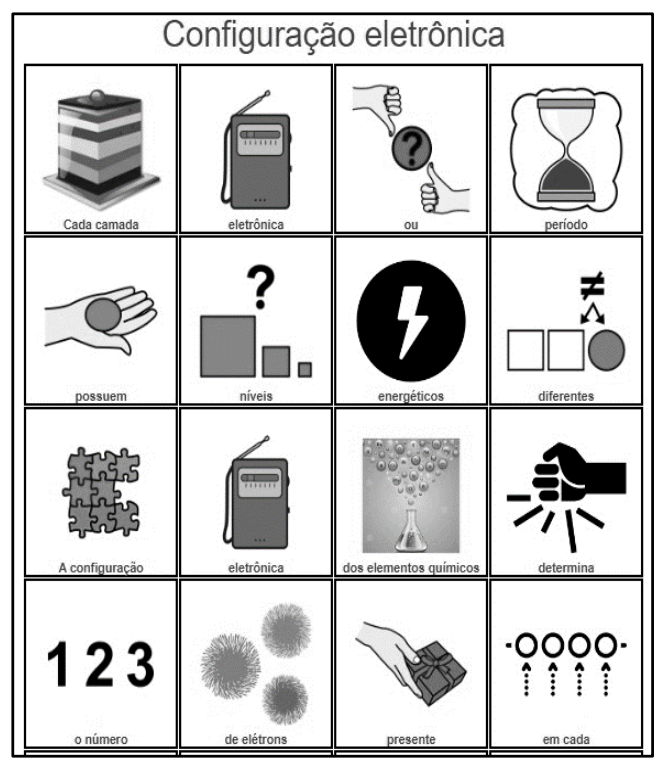

Figura 12 - Distribuição eletrônica (Cap. VIII)

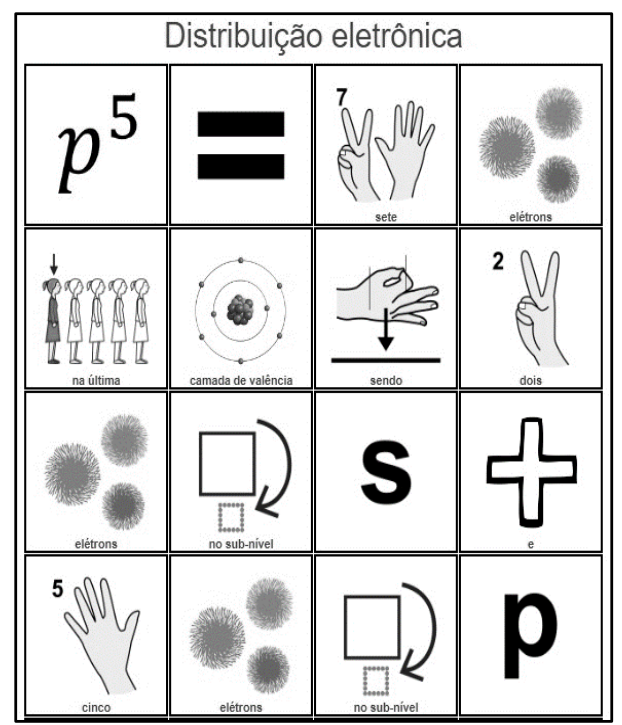

Figura 11 - Orbitais eletrônicos (Cap. VII)

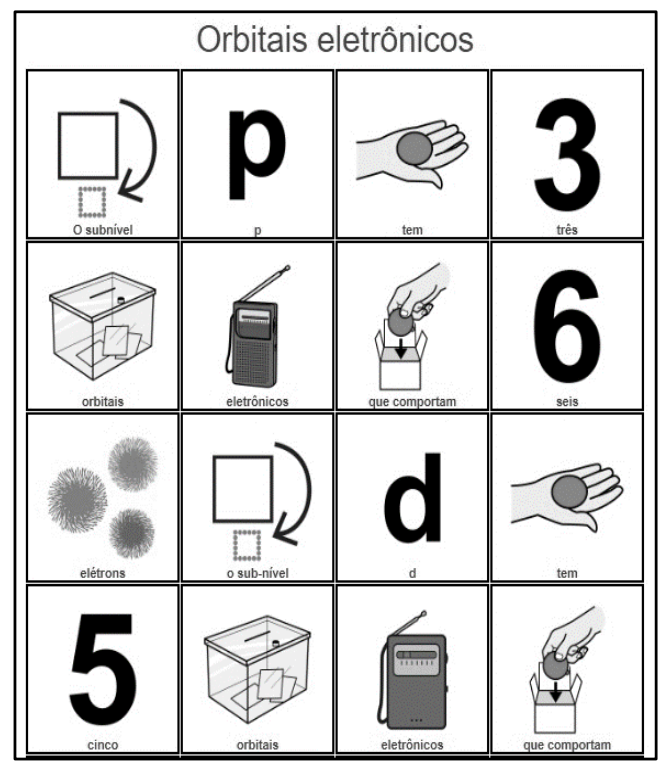

Figura 13 -Raio atômico (Cap. XIX)

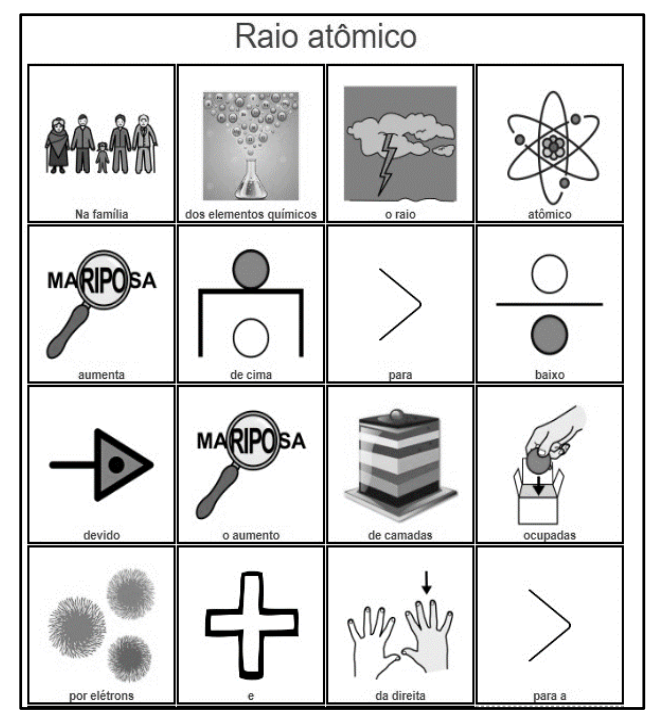



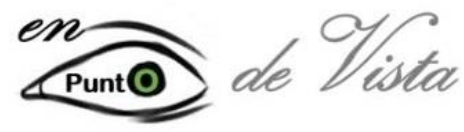

Nos capítulos X e XI, conforme exposto nas Figuras 14 e 15, foram abordados os conceitos de energia de ionização, incluindo definição e exemplos, e de afinidade eletrônica, bem como sua definição e relação com o raio atômico.

Figura 14 -Energia de lonização (Cap. X)

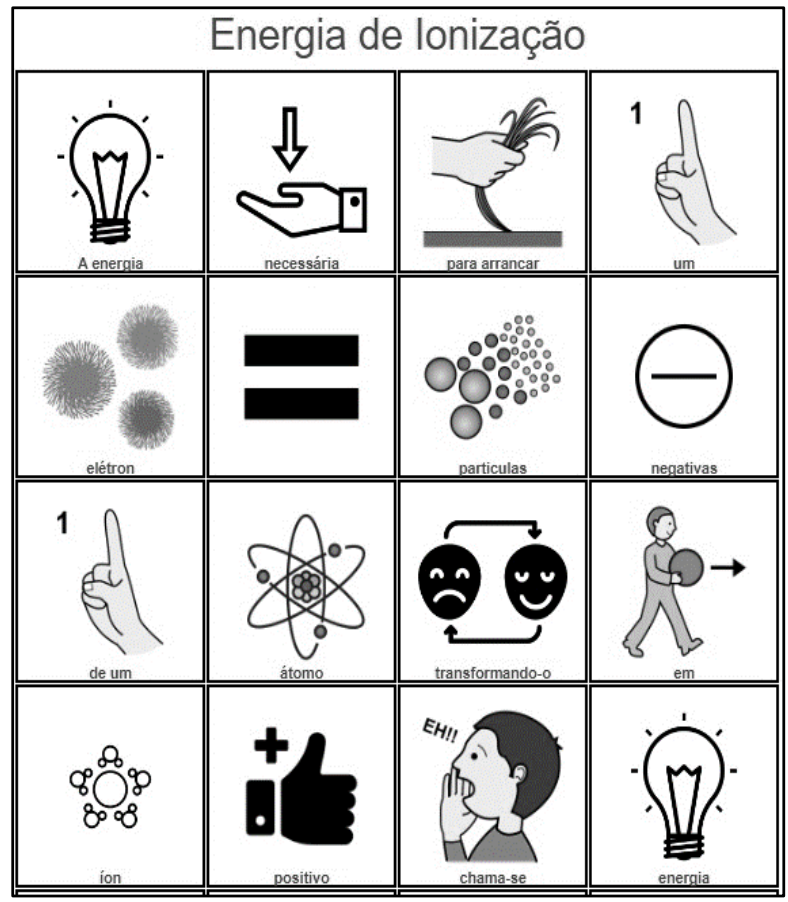

Figura 15 - Afinidade eletrônica (Cap. XI)

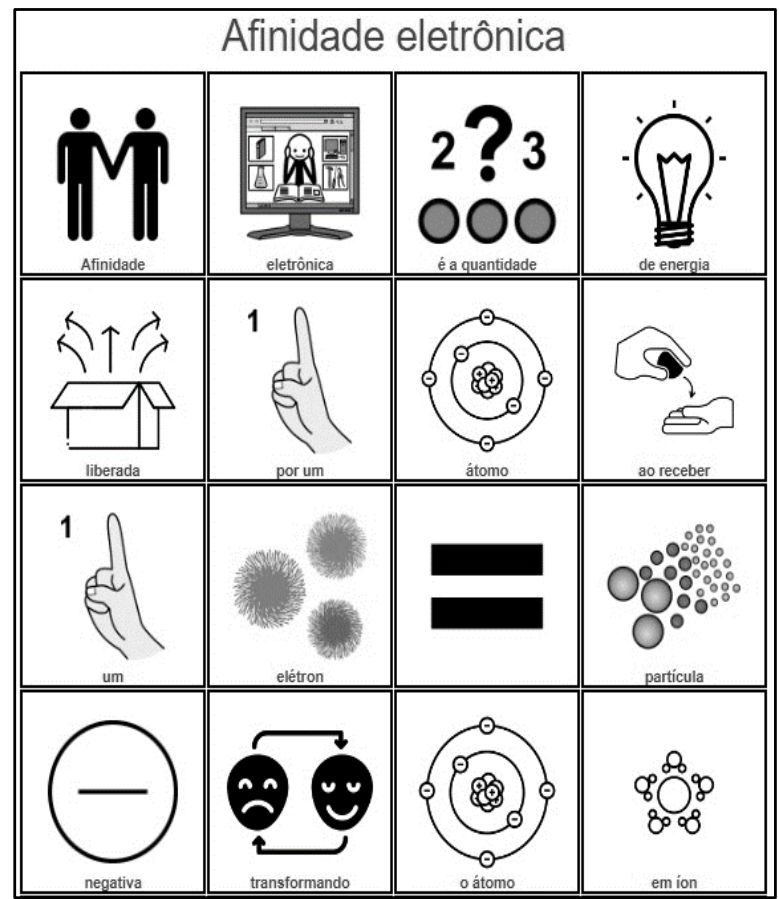

Na confecção da prancha temática procurou-se trabalhar de forma simples e objetiva de modo que o aluno com deficiência intelectual fosse capaz de construir seu próprio conhecimento ao manuseá-la durante as aulas de química. Contudo, a utilização deste recurso não prescinde a atuação do professor de química, muito pelo contrário, o uso da prancha temática no ensino de Tabela Periódica tem como propósito auxiliar tanto o professor na explicação desse conteúdo, quanto o aluno com deficiência intelectual na compreensão de tais conhecimentos, os quais podem ser difíceis de entender quando não são trabalhados de modo contextualizado e adequado a realidade e as limitações de um estudante com deficiência intelectual, levando-os a completa incompreensão do conteúdo e consequentemente não contribuindo em nada para a construção do conhecimento e preparação da vida futura desse discente.

A participação do professor de química no ensino desses alunos é de extrema importância, o recurso proposto não se destina aos professores da sala de atendimento educacional especializado, que infelizmente em muitas escolas tem se tornado um professor 

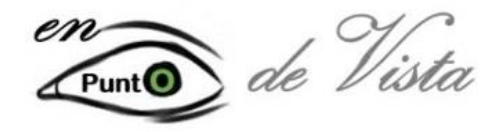

de reforço das disciplinas do ensino regular. Este recurso apesar de poder ser construído em conjunto com o próprio aluno e com o professor do atendimento especial é uma proposta didática para auxiliar o professor de química na sala de aula.

É importante que o professor conheça cada um dos seus alunos (ideal nem sempre possível), assim como, as suas respectivas habilidades e dificuldades, para então desenvolver e utilizar recursos didáticos e metodologias que de fato possam auxiliar seus discentes na compreensão dos conteúdos trabalhados em sala de aula.

Em convergência com essa perspectiva, Sampaio (2017) afirma ser necessário que o professor reflita e esteja ciente de que é preciso ter flexibilidade na sua prática pedagógica, a qual deve considerar além das teorias a serem aprendidas, o contexto no qual ela será desenvolvida e principalmente o aluno com quem ela será desenvolvida, desse modo o uso do recurso didático adequado as especificidades de cada aluno poderão de fato contribuir para o processo de ensino-aprendizagem.

Infelizmente para o ensino de temas ligados as ciências da natureza, como é o caso dos conteúdos de química, poucos são os recursos didáticos construídos dentro da multisensorialidade que possam contribuir de forma efetiva na formação de alunos com necessidades educacionais especiais, principalmente aquelas com deficiência intelectual. Muito dessa realidade deve-se à falta de formação adequada de muitos profissionais responsáveis por ministrar os conteúdos de química, ficando comprometida a inclusão pela falta do devido preparo (CAMARGO; NARDI, 2007; DIAS; SOUZA; CRUZ, 2018).

A prancha temática de comunicação, recurso didático desenvolvido na presente pesquisa, foi aplicada a Roberto, um aluno com deficiência intelectual do $1^{\circ}$ ano do ensino médio, que é bastante comunicativo, possui bom relacionamento com os professores e alunos, apresenta fluência na leitura e algumas dificuldades na escrita, tem bom desempenho nas disciplinas de ciências humanas, entretanto, com relação aos componentes das ciências da natureza que envolvem a utilização de conceitos mais abstratos e cálculos matemáticos o mesmo possui maior dificuldade de aprendizagem.

O aluno participante desta atividade já estudou o conteúdo de Tabela periódica no ano de 2018, quando cursou o $9^{\circ}$ ano do ensino fundamental. A escolha de Roberto levou em consideração o fato dele já ter visto o conteúdo na sala de aula do ensino regular, desse modo foi possível fazer um comparativo entre o nível de conhecimento prévio, oriundo do método de ensino tradicional, e o apresentado após a aplicação do recurso de comunicação alternativa.

Antes da apresentação do recurso de comunicação alternativa foi aplicado ao aluno um questionário/exercício adaptado ao seu nível de compreensão, Figura 3, composto por figuras semelhantes às apresentadas na prancha de comunicação, para avaliar o nível de conhecimento que o mesmo já tinha a respeito do conteúdo de tabela periódica. 


\section{Educação Química}
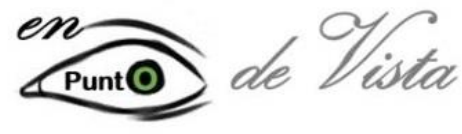

A aplicação da prancha temática, objeto de estudo nesta atividade, foi realizada na sala de atendimento educacional especializado da escola em conjunto com a professora que presta esse atendimento especial. Para tanto foram utilizados como recursos auxiliares duas tabelas periódicas, uma convencional e outra que apresenta figuras de objetos que são constituídos pelos respectivos elementos químicos, chamada de "tabela periódica do cotidiano". Além disso, durante a aplicação da prancha procurou-se sempre levar em consideração o tempo de compreensão do conteúdo por parte do aluno, mantendo sempre o diálogo, para que todas as dúvidas que surgissem fossem sanadas.

Miranda e Pinheiro (2016) analisam que esse momento no qual o aluno com deficiência intelectual expõe suas dúvidas a respeito do conteúdo trabalhado é uma oportunidade para ele desenvolver a sua oralidade, ao verbalizar suas ideias, seu conhecimento, e também de ser ouvido, tornando-se parte integrante do processo de ensinoaprendizagem.

Posteriormente a aplicação da prancha temática foi solicitado a Roberto que ele voltasse a responder o mesmo questionário/exercício, constituído pelas mesmas questões e figuras do questionário anterior, desse modo foi possível verificar se a utilização do recurso proposto contribuiu na aprendizagem desse aluno.

Na Quadro 1 abaixo estão apresentadas as questões que foram feitas ao aluno, bem como a resposta correta e a que foi dada pelo aluno antes e depois da aplicação da prancha temática como recurso didático para o ensino de química.

Quadro 1- Questões e respostas do exercício aplicado ao aluno

\begin{tabular}{cccc}
\hline Questões & Resposta correta & $\begin{array}{c}\text { Resposta do aluno } \\
\text { antes da aplicação do } \\
\text { recurso }\end{array}$ & $\begin{array}{c}\text { Resposta do aluno } \\
\text { após a aplicação do } \\
\text { recurso }\end{array}$ \\
\hline $\begin{array}{c}\text { Onde pode encontrar os } \\
\text { elementos químicos? }\end{array}$ & As 5 figuras & $\begin{array}{c}\text { Identificou apenas uma } \\
\text { figura: alimentos }\end{array}$ & $\begin{array}{c}\text { Identificou apenas } \\
\text { uma figura: } \\
\text { alimentos }\end{array}$ \\
\hline $\begin{array}{c}\text { Qual o elemento químico } \\
\text { presente no ar que respiramos? }\end{array}$ & Oxigênio & Oxigênio & Oxigênio \\
$\begin{array}{c}\text { Qual o elemento químico } \\
\text { presente no sal de cozinha }\end{array}$ & Sódio & Sódio & Sódio \\
$\begin{array}{c}\text { Os elementos químicos } \\
\text { possuem número atômico }\end{array}$ & Diferentes & Iguais & Iguais \\
\hline $\begin{array}{c}\text { Onde os elementos químicos } \\
\text { estão organizados? }\end{array}$ & Na tabela periódica & Na tabela periódica & Na tabela periódica \\
\hline $\begin{array}{c}\text { Na tabela periódica os } \\
\text { elementos químicos estão } \\
\text { organizados em que ordem? }\end{array}$ & Crescente & Crescente & Crescente \\
$\begin{array}{c}\text { Na tabela periódica os } \\
\text { elementos químicos estão }\end{array}$ & Período & Camada de valência & Período \\
\hline
\end{tabular}




\section{Educação Química}

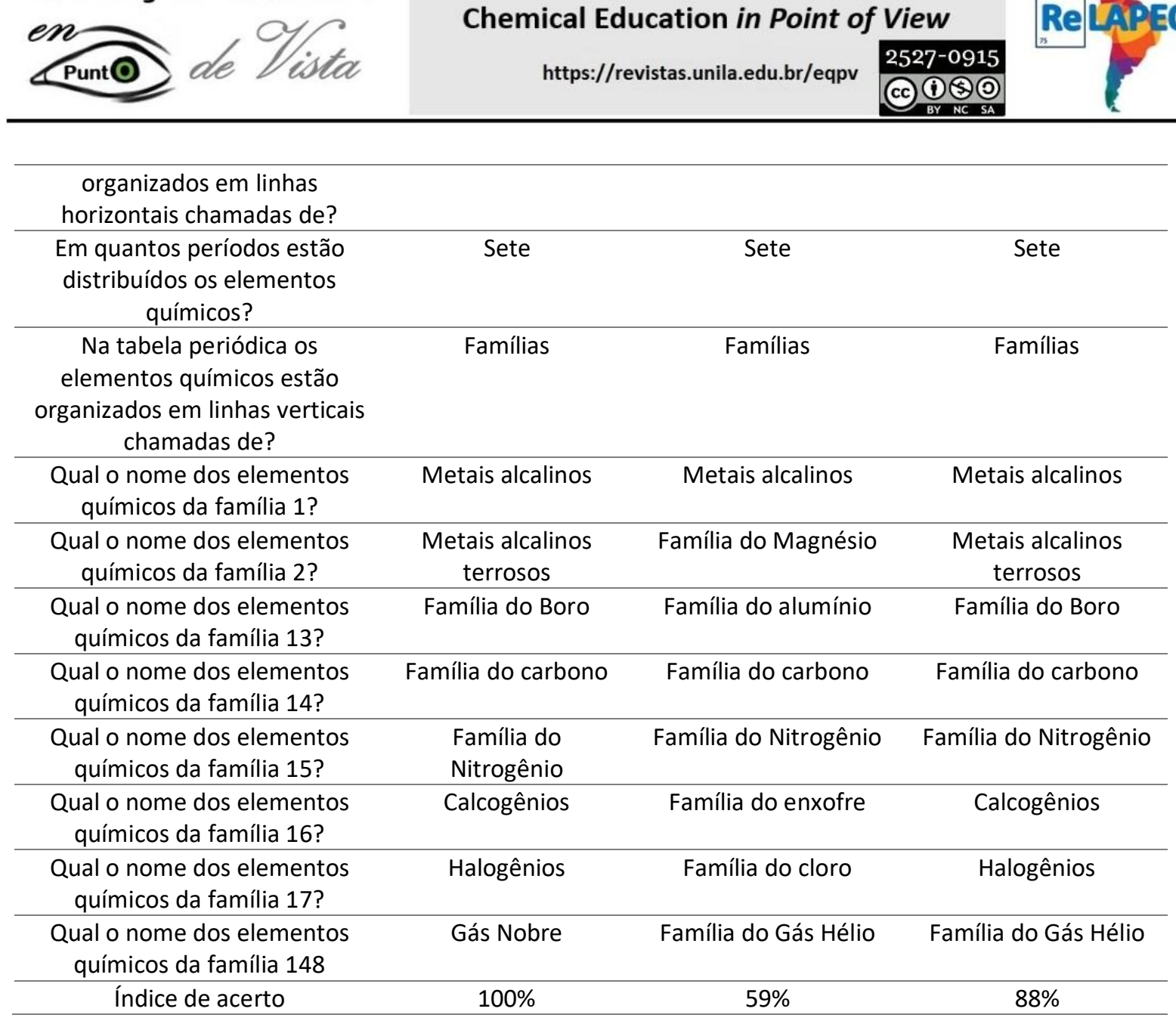

Quando as respostas de Roberto foram analisadas, identificou-se que em se tratando de conceitos básicos a respeito dos elementos químicos e da tabela periódica, o mesmo já possui um bom nível de conhecimento, apresentando um índice de acerto de $59 \%$ antes da aplicação da prancha temática, esse conhecimento foi possivelmente obtido durante o $9^{\circ}$ ano, quando viu pela primeira vez o conteúdo de tabela periódica.

Após a utilização da prancha temática o índice de acerto das questões do exercício subiu para $88 \%$, tal resultado deve-se principalmente ao avanço obtido na nomenclatura das famílias dos elementos químicos, que das oito questões relacionadas a esse tema o nível de acerto subiu de três para sete questões após a aplicação da prancha temática,

É bem verdade que alguns erros se repetiram mesmo após a utilização da prancha temática. A questão número um, por exemplo, retrata bem isso, todas as figuras apresentadas no questionário estão no capítulo I da prancha temática como exemplos de onde podemos encontrar os elementos químicos no nosso dia-a-dia, mas apesar disso o aluno identificou apenas uma única figura e a mesma nos dois momentos, que foi a que representava os alimentos. As demais questões apresentavam apenas uma resposta correta, possivelmente isso levou o aluno a escolher apenas uma das figuras, entretanto vemos que o aluno não foi 

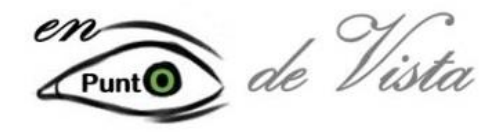

capaz de levantar nenhum questionamento a respeito das demais figuras, as quais também foram trabalhadas com ele durante a aplicação do recurso didático.

Outro erro que se repetiu antes e depois da utilização do recurso foi o não reconhecimento da organização dos elementos químicos na tabela periódica em ordem crescente de número atômico, tal fato deve-se possivelmente a dificuldade que o aluno possui de associação numérica, não sendo capaz de reconhecer que o número 10 é maior que 9, por exemplo.

Apesar do questionário ter sido aplicado imediatamente após o uso da prancha temática, sendo mais fácil o aluno lembrar do conteúdo que havia sido trabalhado, é importante ressaltar que ele demostrava interesse e curiosidade sobre o que seria estudado a cada página que ia sendo apresentada, levantando sempre questionamentos e sanando dúvidas acerca do conteúdo. O uso das figuras tem grande efeito nessa questão, como se tratava de algo novo para o aluno notava-se que as imagens prendiam a sua atenção à medida que o conteúdo ia sendo ministrado.

Para Alencar e Zaporoszenko (2008) durante o processo de confecção das pranchas temáticas de comunicação o ideal seria o professor selecionar as imagens a serem utilizadas em conjunto com o aluno, mas caso isso não seja possível, o professor deverá escolher imagens que retratem da melhor maneira possível a palavra, objeto ou expressão que se deseja transmitir, ou seja, o aluno tem que reconhecer nela (imagem) o que de fato quer expressar e/ou comunicar.

Acredita-se que o aprendizado de Roberto foi além das questões abordadas no exercício, visto que a medida que conceitos novos iam surgindo, dúvidas e questionamentos iam sendo feitos. O próprio aluno afirmou que se o ensino dos demais conteúdos de química fossem através de recursos semelhantes ao desenvolvido nesta pesquisa, o mesmo acreditava que seria mais fácil aprendê-los, resultando em um maior nível de aprendizagem.

De acordo com Mendonça (2015) o uso de recursos didáticos no ensino não só de química, mas de todos os conteúdos escolares, implica em mudanças de paradigmas que visa a educação transformadora em benefício de todos, independentemente de suas limitações, assegurando à alunos com desempenhos diferentes a oportunidade de alcançar o mesmo objetivo em sala de aula, que é a aprendizagem.

A professora de atendimento educacional especializado da escola, que acompanhou de perto a aplicação da prancha temática, também avaliou de forma positiva o instrumento utilizado, considerou a prancha uma excelente ferramenta que poderia ser trabalhada por ela na sala de atendimento educacional especializado, visto que conceitos químicos expressos através de figuras se tornam compreensíveis até para ela, cuja formação é pedagogia.

Além disso, lamentou o fato de que são poucos os professores que procuram desenvolver uma metodologia diferenciada para ensinar aos alunos com necessidades 


\section{Educação Química}

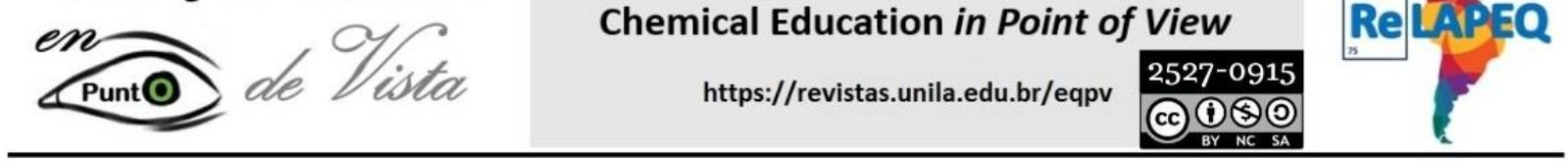

educacionais especiais, que hoje compõem o corpo estudantil da escola, utilizando suas palavras "muitos dos professores lançam apenas palavras ao vento" sem se preocuparem em de fato incluir esses alunos nas suas aulas.

Esta fala é preocupante, a ausência de adaptações curriculares e de ferramentas pedagógicas alternativas podem prejudicar consideravelmente o desenvolvimento acadêmico dos alunos com deficiência intelectual. Nesta mesma linha, Sampaio (2017) afirma que estratégias e recursos didáticos são importantes para todos os alunos com ou sem nenhuma deficiência, porém para o aluno com deficiência, eles podem ser essenciais para ter acesso ao conhecimento.

Com o uso da prancha temática e de outros recursos e metodologias de ensino não espera-se que o nível de aprendizagem e de conhecimento de um aluno com deficiência intelectual equipare-se ao dos demais estudantes que não possuem nenhuma necessidade educacional especial, o que pode acontecer, mas tem como finalidade incluir e tornar esse grupo de alunos especiais parte integrante do processo de ensino-aprendizagem que ocorre dentro da sala de aula do ensino regular, dando-lhes a oportunidade de aprender química independente de suas limitações. Dentro da própria deficiência intelectual há alunos com maior facilidade em compreender determinado conteúdo do que outros, assim como ocorre com os demais estudantes, cada indivíduo desenvolve competências e habilidades específicas que devem ser respeitadas e consideradas.

No pouco tempo disponível em que trabalhou-se a prancha temática com Roberto, já foi possível verificar um avanço no que diz respeito a compreensão e aprendizagem do conteúdo de tabela periódica, acredita-se que o uso contínuo deste recurso e de outros semelhantes para trabalhar os demais conteúdos de química proporcionaria um aumento significativo no rendimento escolar dos alunos com deficiência intelectual que hoje estão inseridos na escola de ensino regular onde esta atividade foi desenvolvida.

O impacto positivo da prancha de comunicação também foi relatado por Silva (2013) que obteve resultados satisfatórios ao utilizar este recurso com versatilidade, a partir de palavras em placas imantadas, livro da vida e de texturas, com finalidade de auxiliar uma aluna com deficiência múltipla inserida no ensino regular nas atividades de leitura e escritas de palavras, estimulação tátil e sensorial. O uso de tais recursos proporcionou o desenvolvimento de habilidades expressivas não verbais; emissão de vogais e sílabas, expressão facial, gestos indicativos, representativos e de imitação, ampliando a capacidade de comunicação dessa aluna no âmbito escolar, social, familiar e terapêutico.

Outra experiência bem sucedida foi descrita por Crocetti (2014), que confeccionou em conjunto com os professores da educação infantil pranchas de comunicação alternativa, semelhante a desenvolvida na presente pesquisa, destinada a crianças com deficiência intelectual que apresentavam dificuldades severas de comunicação e de aprendizagem, as 


\section{Educação Química}
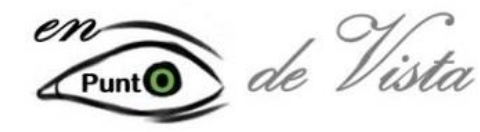

quais foram utilizadas para favorecer a expressão das necessidades dos alunos e sua aquisição de conteúdos das disciplinas de matemática e ciências.

Dessa forma, a flexibilidade de confecção deste tipo de recurso permite que ele possa ser utilizado pelos mais diversos tipos de alunos em todos os níveis de escolarização, desde a educação infantil até o ensino médio, uma vez que a construção da prancha de comunicação deve considerar as especificidades de cada estudante.

\section{CONSIDERAÇÕES FINAIS}

A proposta do presente trabalho foi construir uma prancha temática com o objetivo de auxiliar os professores no ensino de química para alunos com deficiência intelectual. Acredita-se que este recurso alternativo de comunicação pode se constituir em um suporte para o ensino de conteúdos considerados complexos por terem uma natureza abstrata e aparentemente desvinculada ao contexto habitual das pessoas. Visto que, ao confeccionar a prancha é dado prioridade ao uso de figuras e elementos integrantes da rotina diária.

Ao considerar as especificidades do processo de aprendizagem do aluno com deficiência intelectual, identifica-se a relevância de adotar estratégias pedagógicas permeadas por pistas visuais e significantes para facilitar a apropriação dos conteúdos da disciplina de Química. Pois, os déficits nas suas habilidades intelectuais não podem ser justificativas para privá-los de conceitos científicos relevantes à sua formação e que atuam como instigadores de formas mais elaboradas de raciocínio.

Isto foi demonstrado com a aplicação da prancha em um aluno com deficiência intelectual, o qual apresentou uma série de dúvidas e questionamentos evocados pelo instrumento e que extrapolaram o material abordado, funcionando como gatilho para a emergência de pensamentos mais complexos e construção de novos conhecimentos. Além disso, o uso da prancha, articulado à tabela periódica convencional, promoveu uma melhora significativa na compreensão dos conhecimentos vinculados a esta matéria.

Outra questão indicadora da contribuição deste recurso foi a avaliação do aluno participante da atividade e da professora da sala de atendimento educacional especializado, ambos consideraram que o método adotado tornou mais compreensível os conceitos trabalhados. Embora, não se possa atribuir exclusivamente ao uso da prancha temática a melhora do desempenho do aluno participante em relação ao questionário aplicado, visto que outros instrumentos foram utilizados, os dados assinalados acima acerca da atuação do aluno em resposta ao estímulo da prancha e os relatos positivos dele e da professora corroboraram a efetividade desta ferramenta. 


\section{Educação Química}
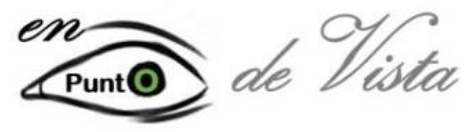

É importante assinalar o cuidado na elaboração do questionário para avaliar conhecimentos sobre a tabela periódica, visto que, não apenas o ensino voltado para grupos com necessidades educativas especiais requer do docente adaptações nas metodologias abordadas, mas, o processo de avaliação também deve estar alinhado às características do discente. Neste sentido, o instrumento usado adotou perguntas curtas e objetivas associadas a imagens que materializavam os conceitos solicitados.

$\mathrm{O}$ aporte teórico abordado e os dados obtidos sinalizam a prancha temática como uma possibilidade para tornar o ensino mais didático; considerando o seu baixo custo e os benefícios de seu uso, a difusão do seu uso para trabalhar conteúdos específicos torna-se importante, pois se apresenta como uma ferramenta acessível e facilitadora da aquisição de conhecimentos.

\section{REFERÊNCIAS}

AMERICAN PSYCHIATRIC ASSOCIATION. Manual Diagnóstico e Estatístico de Transtornos Mentais: DSM -5. (2014). Porto Alegre: Artmed. $5^{\circ}$ ed., Porto Alegre: Artmed, 2014.

ANACHE, A. A., RESENDE, D. A. R. Caracterização da avaliação da aprendizagem nas salas de recursos multifuncionais para alunos com deficiência intelectual. Revista Brasileira de Educação, v. 21, n. 66, p. 569591, 2016.

ARAÚJO, S. L. S.; ALMEIDA, M. A. Contribuições da consultoria colaborativa para inclusão de pessoas com deficiência intelectual. Revista Educação Especial, v. 27, n. 49 p. 341-351, 2014.

ALENCAR, G. A. R., ZAPOROSZENKO, A. Comunicação alternativa e paralisia cerebral: Recursos didáticos e de expressão. Caderno pedagógico: educação especial. Universidade Estadual de Maringá. p. 22, 2008. Disponível em:< http://www.gestaoescolar.diaadia.pr.gov.br/arquivos/File/producoes_pde/md ana_zaporoszenko.pdf $>$. Acesso em: 27 abr. 2020.

AIDD- Association on Intellectual and Develpmental Disabilities. Definition of Inte10 abr. 2020.

BRASIL. Ministério da educação. Política Nacional de Educação Especial na Perspectiva da Educação Inclusiva. 2008, p.15.

BRASIL. Ministério da educação. Diretrizes nacionais para a educação especial na educação básica. Secretária de educação especial. 2001, p. 79.

BRASIL. Lei de Diretrizes e Bases da Educação Nacional. Lei n. 9.394, 20 de dezembro de 1996. Brasília: Ministério da Educação, 1996.

BRASIL. Constituição da República Federativa do Brasil. Brasília: Senado Federal, 1988.

CAMARGO, E. P.; NARDI, R. Planejamento de atividades de ensino de física para alunos com deficiência visual: dificuldades e alternativas. Revista Eletrónica de Enseñanza de las Ciencias, v. 6, n. 2, p. 378-401, 2007. 


\section{Educação Química}
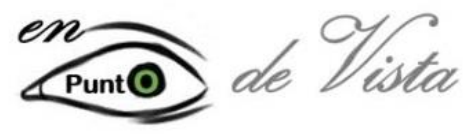

CROCETTI, L. D. W., NASCIMENTO, L. M. Comunicação Alternativa Ampliada (CAA) para Alunos com Deficiência Intelectual: como tema da formação do professor de Educação Infantil. Disponível em:

<http://www.diaadiaeducacao.pr.gov.br/portals/cadernospde/pdebusca/producoes_pde/2014/2014_ufpr_ed especial_artigo_lilian_daisy_weber_crocetti.pdf> Acesso em: 09 ago. 2018.

DIAS, A. C. L., SOUZA, G. F. R., CRUZ, F. A. O. Comunicação alternativa no ensino de física: uma proposta de abordagem de eletricidade. Revista Electrónica de Investigación En Educación En Ciencias. n. 1, p. 15-23, 2018.

GLAT, R; FERNANDES E M. Da educação segregada à educação inclusiva: uma breve reflexão sobre os paradigmas educacionais no contexto da educação especial brasileira. Revista Inclusão, n. 1, p.1-6, 2005.

HONORA, M.; FRIZANCO, M. Esclarecendo as deficiências: aspectos teóricos e práticos para contribuir com uma sociedade inclusiva. $1^{\circ}$ Ed. São Paulo: Ciranda Cultural Editora e Distribuidora, 2008.

JOHNSON. R.M. The picture communication symbols guide. Editora Mayer-Johnson, 1998.

MENDONÇA, A. A. S. (2015). Educação especial e educação inclusiva: dicotomia de ensino dentro de um mesmo processo educativo. In: VIII Encontro de pesquisa em educação. III Congresso internacional trabalho docente e processos educativos, 2015.

MELETTI, S. M. F.; BUENO, J. A escolarização de alunos com deficiência intelectual: análise dos indicadores nacionais brasileiros. Políticas públicas, escolarização de alunos com deficiência e pesquisa educacional, $1^{\circ}$ Ed. São Paulo: JUNQUEIRA \& MARIN 2013.

MIRANDA, A. D., PINHEIRO, N. A. M. O ensino da Matemática ao deficiente intelectual: projetos de trabalho em uma perspectiva contextualizada e interdisciplinar. Revista Educação Especial, v. 29, n. 56, p. 695-708, 2016.

SAMPAIO, L. F. Educação Inclusiva: Uma proposta de ação na Licenciatura em Química. 2017. 127 f. Dissertação (Mestrado Profissional em Ensino de Ciências). Universidade de Brasília, 2017.

SILVA, F. R. P. Comunicação suplementar e alternativa no atendimento educacional especializado de uma aluna com deficiência múltipla. 2013. 85 f. Trabalho de Conclusão de Curso, (Pedagogia), Centro Universitário Católico Salesiano Auxilium, 2013. 


\section{Educação Química}
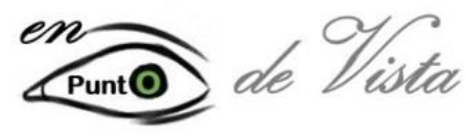

\section{RESUMO}

A compreensão dos conceitos científicos de química são um desafio para os alunos do ensino médio, principalmente para os alunos com deficiência intelectual. Reconhece-se, portanto, a necessidade de desenvolver novas metodologias que se adequem as especificidades desse grupo. A presente pesquisa teve como objetivo confeccionar uma prancha temática para auxiliar alunos com deficiência intelectual no ensino/aprendizagem da tabela periódica. Para tanto, utilizou-se o software picto4me na escolha e disposição das figuras da prancha temática. O conteúdo de tabela periódica foi trabalhado observando-se a sequência cronológica dos livros didáticos. Depois de construída, a prancha temática foi utilizada por um aluno com deficiência intelectual e o seu nível de aprendizagem foi verificado através do aumento do número de acertos das questões dispostas em um exercício específico. Os resultados obtidos evidenciam a validade da prancha temática, pois além de auxiliar no aprendizado, gerou novos questionamentos no estudante, caminho para evocar pensamentos mais elaborados.

\section{RESUMEN}

Comprender los conceptos científicos de la química es un desafío para los estudiantes de secundaria, especialmente para los estudiantes con discapacidad intelectual. Por tanto, se reconoce la necesidad de desarrollar nuevas metodologías que se adapten a las especificidades de este grupo. Esta investigación tuvo como objetivo realizar un tablero temático para ayudar a los estudiantes con discapacidad intelectual en la enseñanza / aprendizaje de la tabla periódica. Para ello, se utilizó el software picto4me en la elección y disposición de las figuras en el tablero temático. El contenido de la tabla periódica se trabajó observando la secuencia cronológica de los libros de texto. Una vez construido, el tablero temático fue utilizado por un alumno con discapacidad intelectual y se verificó su nivel de aprendizaje aumentando el número de respuestas correctas a las preguntas dispuestas en un ejercicio específico. Los resultados obtenidos evidencian la vigencia del tablero temático, pues además de ayudar en el aprendizaje, generó nuevas preguntas para el alumno, una forma de evocar pensamientos más elaborados. 